\title{
Does Linguistic Similarity Affect Early Simultaneous Bilingual Language Acquisition?
}

\author{
Anja Gampe \\ Post-Doc, Institute of Socio-Economics, University of Duisburg-Essen, \\ Duisburg, Germany \\ anja.gampe@uni-due.de \\ Antje Endesfelder Quick \\ Lecturer, Institute of British Studies, University of Leipzig, Leipzig, Germany \\ antje.quick@uni-leipzig.de
}

\author{
Moritz M. Daum \\ Professor, Department of Psychology and Jacobs Center for Productive Youth \\ Development, University of Zurich, Zurich, Switzerland \\ moritz.daum@uzh.ch
}

\begin{abstract}
It is well established that $\mathrm{L} 2$ acquisition is faster when the $\mathrm{L} 2$ is more closely related to the learner's Li. In the current study we investigated whether language similarity has a comparable facilitative effect in early simultaneous bilingual children. The similarity between each bilingual child's two languages was determined using phonological and typological scales. We compared the vocabulary size of bilingual toddlers learning different pairs of languages. Results show that the vocabulary size of bilingual children is indeed influenced by similarity: the more similar the languages, the larger the children's vocabulary.
\end{abstract}

\section{Keywords}

bilingual language acquisition - language similarity - vocabulary development lexicon size 
Most of the world's children grow up learning two or more languages simultaneously (Grosjean, 1982). Input is naturally divided between the two languages, and consequently the frequency of input is less than $100 \%$ for each of the languages (Unsworth, 2015). This input reduction has been considered to be one of the primary factors responsible for differences between monolinguals and bilinguals in development (Hoff, Welsh, Place, and Ribot, 2014; e.g., Pearson, Fernández, and Oller, 1993; Thordardottir, 2011). A further aspect often related to this issue is the differing levels of proficiency in the two languages caused by the unequal input amounts. Balanced bilingualism may be an ideal but hardly exists (see Silva-Corvalán and Treffers-Daller, 2015, for an overview on the issue of language dominance).

One aspect that is strongly affected by bilingualism is vocabulary size. This effect has received repeated support from studies using the classical approach of comparing bilingual to monolingual language development. A large body of research has shown that, in each of their languages, bilingual children and adults tend to know fewer words than monolinguals do (Bialystok and Luk, 2012; Bialystok, Luk, Peets, and Yang, 2010). However, it is notable that the combined vocabularies of bilingual children are of comparable size to monolingual vocabularies (De Houwer, Bornstein, and Putnick, 2014; Hoff et al., 2012; Pearson et al., 1993). Research on bilingual vocabulary development has addressed the role of various factors in bilingual vocabulary learning, such as phonological development and word learning mechanisms, influence of socio-economic factors (SES), minority or majority status of the languages (Gathercole and Thomas, 20o9; Miser and Hupp, 2012), and the amount of exposure to each language (Byers-Heinlein, Fennell, and Werker, 2013; Fennell, Byers-Heinlein, and Werker, 2007; Graf Estes and Hay, 2015; Kalashnikova, Mattock, and Monaghan, 2014).

One of the most important factors is reportedly the amount of exposure: the more words children hear, the more words they know (Hart and Risley, 1995) and the more frequently a word is heard, the earlier it is learned (Goodman, Dale, and Li, 2008; Naigles and Hoff-Ginsberg, 1998; Schwartz and Terrell, 1983). In bilingual vocabulary development, the "number of words learnt in each language is to a large extent proportional to the amount of time spent with speakers of that language" (Cattani et al., 2014; David and Wei, 2008; Hoff et al., 2012; Pearson, Fernandez, Lewedeg, and Oller, 1997: 51; Place and Hoff, 2011). However, some of the words bilinguals are exposed to are cognates, i.e., words phonologically similar between the two spoken languages. Interestingly, the vocabularies of young bilingual children comprise a relatively higher 
proportion of translational equivalents (words children know in both languages) that are cognate words (e.g., English boat and German Boot) as compared to translational equivalents that are non-cognates (e.g., English biscuit and German Keks, Bosch and Ramon-Casas, 2014; Schelletter, 2002). This suggests that similarity in the phonological forms of two words across languages eases the learning of each. This finding is in line with the assumptions about language acquisition in a usage-based approach.

Under a usage-based model, similarity between words and constructions is an important aspect for categorization. It is the basis for emerging exemplars and their links to other exemplars (e.g., Bybee, 2010). Children learning language map similar tokens of linguistic experience onto each other to establish cognitive representations (exemplar) of its elements and structures as well as forming various types of links (cf. Bybee, 2010). Similarities between words can be based on phonetic and semantic dimensions (Bybee, 2010; Pierrehumbert, 2003) and link phonetically and semantically similar words and word strings to each other creating a dynamic network in which words (linguistic signs) are interconnected. At the same time, each experience with a token has an impact on its cognitive representation and consequently on its mental entrenchment (Schmid, 2017). That is, increased frequency of an element or a structure increases the strength of its representation and associative links to similar structures and signs. Consequently, it will be more easily activated than lower frequency items, which generally will be less well entrenched. Although it remains unclear whether bilinguals develop one exemplar for two elements similar in both languages or one for each language, similarity between items has a facilitating effect on acquisition in both scenarios (e.g., Hartsuiker, Pickering, and Veltkamp, 2004). For example, if we assume that one exemplar is stored for both languages due to phonological and semantic similarity, then any occurrence in either language will strengthen its entrenchment, making its activation easier and its production more likely. On the other hand, if two exemplars are stored in a network, one for each language, due to the facilitating effect of similarity, any occurrence of either form should still affect the strength of their associative links. Thus, if two languages share many cognates, more of their stored representations are likely to be activated due to stronger connections among the words even when the other language is being spoken. The same rationale could also apply to the acquisition of morpho-syntactic structures across languages. If languages share structures, children could acquire these structures earlier since their representations receive support from both languages, which affects entrenchment and activation as well. On the other hand, if words or structures across languages only share form or function, their links are weaker resulting in lower entrenchment levels, meaning they are more 
difficult to be activated. That similar words and analogous morpho-syntactic structures are learnt faster in each of the two languages has recently been shown by Bosch and Ramon-Casas (2014), and Perez-Pereira (2008). Bosch and Ramon-Casas (2014) suggest that in the case of identical word forms in the two languages, token frequency of a word increases and thus eases word learning. Similar processes might - on a larger scale - affect overall vocabulary size. That is, bilingual children learning different languages might know more, or fewer, words in each of their languages depending on how similar the word stocks of their two languages are. Perez-Pereira (2008) showed that children who were learning Galician and Spanish, two highly similar languages, exceeded monolingual peers in both vocabulary and morpho-syntax scores. Apparently, similarity had a booster function for each language and had strengthened the connections between similar exemplars in the network.

To our knowledge, the question of whether bilingual children learning different language constellations achieve different vocabulary scores has not yet been addressed. The study by Cote and Bornstein (2014) is the only one to compare the vocabulary scores across bilingual 2o-month-olds from three language groups (Spanish-English, Korean-English, and JapaneseEnglish). The authors were interested in whether relative input factors such as number of interlocutors or level of acculturation of the mother could predict language acquisition, and found that the vocabulary sizes did not differ across the three groups in English and the heritage languages. In contrast, research on adult second-language (L2) learning has demonstrated strong effects of the learners' first languages (L1) on L2 language proficiency (Cysouw, 2013; Schepens, Slik, and Hout, 2013; Van der Slik, 2010). For example, the phonological similarity between the first languages of immigrants (35 different languages) and their L2 influences immigrants' language proficiencies, such as content, correctness, wording, pronunciation, pace, vocabulary, register, coherence, and word order (Schepens et al., 2013; see also Van der Slik, 2010). Similarly, a more comprehensive measure of language similarity based on the phonological and morpho-syntactic features reported for many languages in the World Atlas of Languages (WALs, Dryer and Haspelmath, 2013) was observed to correlate with L2 learners' language proficiency (Cysouw, 2013). In his analysis, Cysouw (2013) included factors such as typological similarity, geographical distance, orthographic similarity, size of the orthographic system, and genealogical similarity. He found that the strongest predictors of L2 proficiency were typological similarity and orthographic similarity. Note that Cysouw's (2013) study differs from Van der Slik et al.'s $(2010,2013)$ in that Cysouw measured the effect of the 
same L1 (English) on learners' proficiency in various L2s, while Van der Slik and colleagues measured the effect of various Lis on learners' proficiency in the same L2 (Dutch). Thus, the effect of language similarity on L2 learning appears to be robust.

In the current study we analyze the influence of language similarity on bilingual children's vocabulary skills. We assessed children's vocabulary using a parental questionnaire, a method that has been proven to be reliable in that parents are accurate in judging their children's linguistic competence (see Szagun's et al., 2009, on test-retest reliabilities, and Dale, 1991, on validity to laboratory measures in monolinguals, and Marchman and Martínez-Sussmann, 2002, in bilinguals).

Based on the assumptions of usage-based linguistics and the findings from the L1 and L2 learning research reported above, it seems possible that structural and semantic similarity already influence bilingual children's lexical skills at an early stage in their development. Since languages can be similar or different on various levels of language organization, including grammatical, phonological, and lexical levels (Borin, 2013; Cysouw, 2013), we used two measures of language similarity that have recently been used in L2 research. First, following Van der Slik (2010) we used a measure of lexico-phonological similarity based on the ASJP database (Holman et al., 2011; Wichmann, Holman, Bakker, and Brown, 2010). Second, following Cysouw (2013), we used the World Atlas of Languages (WALS, Dryer and Haspelmath, 2013) to compute a measure of morpho-syntactic similarity. The children's language skills were administered by parental questionnaires (cf., e.g., Perez-Pereira, 2008) and then correlated with the two measures of language similarity. We focused on 18- to 36 -month-old bilingual children, since for this age range previous research demonstrated phonological similarity effects on lexicon composition (Bosch and Ramon-Casas, 2014; Schelletter, 2002). We hypothesized that language similarity affects bilingual vocabulary skills in ways similar to how it influences L2 learning.

\section{Study 1}

In our first study we were concerned with the question whether lexico-phonological similarity and morpho-syntactic similarity affects bilingual children's lexical skills between the age of 18 to 30 months. We analyzed the influence of language similarity on the bilingual children's Swiss German vocabulary size by using a parental checklist. 


\subsection{Method \\ 2.1.1 Participants}

Two hundred and four simultaneous bilingual children aged 18 to 30 months ( $\mathrm{M}=23$ months, $\mathrm{SD}=3.89$, 113 girls, 91 boys) participated in the study. Most of the children grew up in middle-class families in Switzerland. The parents' highest educational level was used as a proxy for socio-economic status and recorded using a questionnaire (mothers: $\mathrm{M}=8.127, \mathrm{SD}=2.692$; fathers: $\mathrm{M}=7.912$, $\mathrm{SD}=2.751$; where " 10 " is equivalent to a university degree). Only families in which one parent spoke Swiss German and the other parent spoke a different language were recruited. The children's exposure to Swiss German was estimated based on both parents' weekly working hours. ${ }^{1}$ On average the children's exposure rate to Swiss German was $75 \%(\mathrm{SD}=8.47 \%)$ of their waking time. The families were recruited from a database of parents who had volunteered to participate in child development studies. The families received a small gift such as a picture book to recompense them for the participation. The university's ethics committee approved the study.

\subsubsection{Materials and Procedure}

The children's lexical skills were assessed using parental questionnaires. The parents filled out the Swiss German translation of the word list from the Standard German MacArthur CDI questionnaire (FRAKIS; Szagun, Stumper, and Schramm, 2009). For each of the vocabulary items (including 509 openclass words and 91 closed-class words), the parents indicated whether their child had already produced it, (only) comprehended it, or neither produced nor comprehended it. We used the number of words in the children's productive vocabulary as an indicator for the children's linguistic skills. It could range from o to 6oo, and this was the dependent variable in our study.

The similarity between the languages of each bilingual child was first determined with respect to the lexico-phonological dimension and then to the morpho-syntactic dimension (see Table 1).

1 The basis of the estimation of the children's exposure to Swiss German were the Swissspeaking parent's working hours. We assumed that both parents spent equal amounts of time speaking to their child when at home. We calculated the following exposure rate for Swiss German:

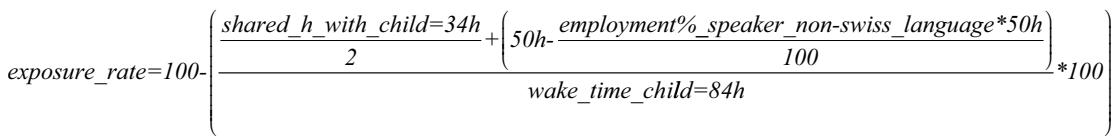


TABLE 1 Language groups in Study 1. Language similarity scores for both measures of language similarity, number of children per language group and mean age of the children per language group. Boldface written languages indicate the languages used in Study 2

\begin{tabular}{lccccc}
\hline $\begin{array}{l}\text { Language } \\
\text { group }\end{array}$ & WALS-similarity & AsJP-similarity & $\begin{array}{c}\text { Number of } \\
\text { children }\end{array}$ & \multicolumn{2}{c}{ Age } \\
\hline Standard & & & 63 & 23.09 & 3.92 \\
German & $\mathbf{1 . 0 0}$ & $\mathbf{5 0 8 6}$ & & & \\
Dutch & & & & 21.00 & 3.26 \\
English & .878 & 6912 & 7 & 23.19 & 3.76 \\
Swedish & .647 & 7129 & 2 & 20.50 & 2.12 \\
Serbian & .629 & 7259 & 12 & 21.83 & 3.48 \\
Czech & .529 & 8742 & 5 & 26.40 & 3.78 \\
Romansh & .500 & 8960 & 5 & 22.60 & 4.72 \\
Slovenian & - & 8980 & 2 & 26.50 & 0.71 \\
Italian & .777 & 9089 & 39 & 23.61 & 4.15 \\
Russian & .692 & 9190 & 4 & 21.25 & 2.98 \\
Portuguese & .700 & 9250 & 3 & 23.00 & 4.35 \\
Polish & .727 & 9300 & 4 & 21.25 & 3.94 \\
French & .571 & 9378 & 16 & 21.87 & 3.82 \\
Spanish & .686 & 9381 & 14 & 22.21 & 3.88 \\
Hungarian & .591 & 9506 & 1 & 25.00 & - \\
Xhosa & .372 & 9659 & 1 & 27.00 & - \\
Turkish & - & 9869 & 3 & 22.66 & 3.21 \\
Japanese & .372 & 9947 & 1 & 28.00 & - \\
Georgian & .354 & 10097 & & 18.00 & - \\
& .416 & 10108 & & & \\
\hline
\end{tabular}

Note. All children learned Swiss German in addition to one of the languages in the list.

The lexico-phonological similarity measure was taken from the ASJP database (Holman et al., 2011; Wichmann et al., 2013), which uses the 40 most stable lexical items from Swadesh's 10o-item list (Swadesh, 1955). These are items with the least formal variation in well-established genetic groups and include words such as I, you, name, hand, path, sun, etc. The lexico-phonological similarity measure is based on the Levenshtein distance between the translational equivalents of these 40 items (for details, see Holman et al., 2011). ${ }^{2}$ The morpho-syntactic similarity measure was determined using the WALS (Dryer and Haspelmath, 2013). Following Cysouw (2013), we computed the relative similarity of each child's two languages as Hamming distance based on the number of shared WALs features in morphology (like Inflectional Synthesis of the Verb, Case Syncretism) and word order (like Order of Subject, Object and Verb,

2 Note that the ASJP database only contains the Bernese Swiss dialect. The measure of language distance used in our analyses is thus only an approximation. 
Order of Demonstrative and Noun) divided by the total number of features compared.

\subsection{Results and Discussion}

First, the children's vocabulary score was correlated with the ASJP similarity measure. A partial correlation (controlling for age, parental education and language exposure) between the children's vocabulary scores and the ASJP similarity revealed a small but significant similarity effect $(r=-.154, p=.036)$. Second, the children's vocabulary score was correlated with the wALS similarity scores. A partial correlation (controlling for age, parental education and language exposure) between the children's vocabulary score and the wALs similarity also revealed a small but significant similarity effect $(r=.141, p=.049)$. Figure 1 shows the children's vocabulary scores with the ordered ASJP and WALS similarity scores. The more similar the languages are (the further left in the figure), the more words children produce.

The results show that language similarity affects young bilingual children's vocabulary skills. However, the effect appears to be smaller (explaining about $3 \%$ of the variance) than the language similarity effect reported by Schepens et al. (2013). In their sample, AsJP similarity accounted for as much $10.6 \%$ of the variance of the adults' L2 proficiency. Another difference between the language similarity effect in our bilingual sample and the language similarity effect reported for L2 learning is that in L2 learning the affected language is the "weaker" language while in the current study we assessed the children's vocabulary scores only in their stronger language, namely Swiss German. It is a majority language, to which the children were exposed for $75 \%$ of their waking time on average according to our estimate. It is possible that language similarity affects the bilingual children's weaker, i.e., less frequently heard, language more. Therefore, assessing both languages' vocabulary might disentangle whether language similarity affects both languages or just one.

In Study 2, we analyzed the influence of language similarity not only on the children's Swiss German vocabulary scores but also on their vocabularies in their other languages as well as the translational equivalents. 

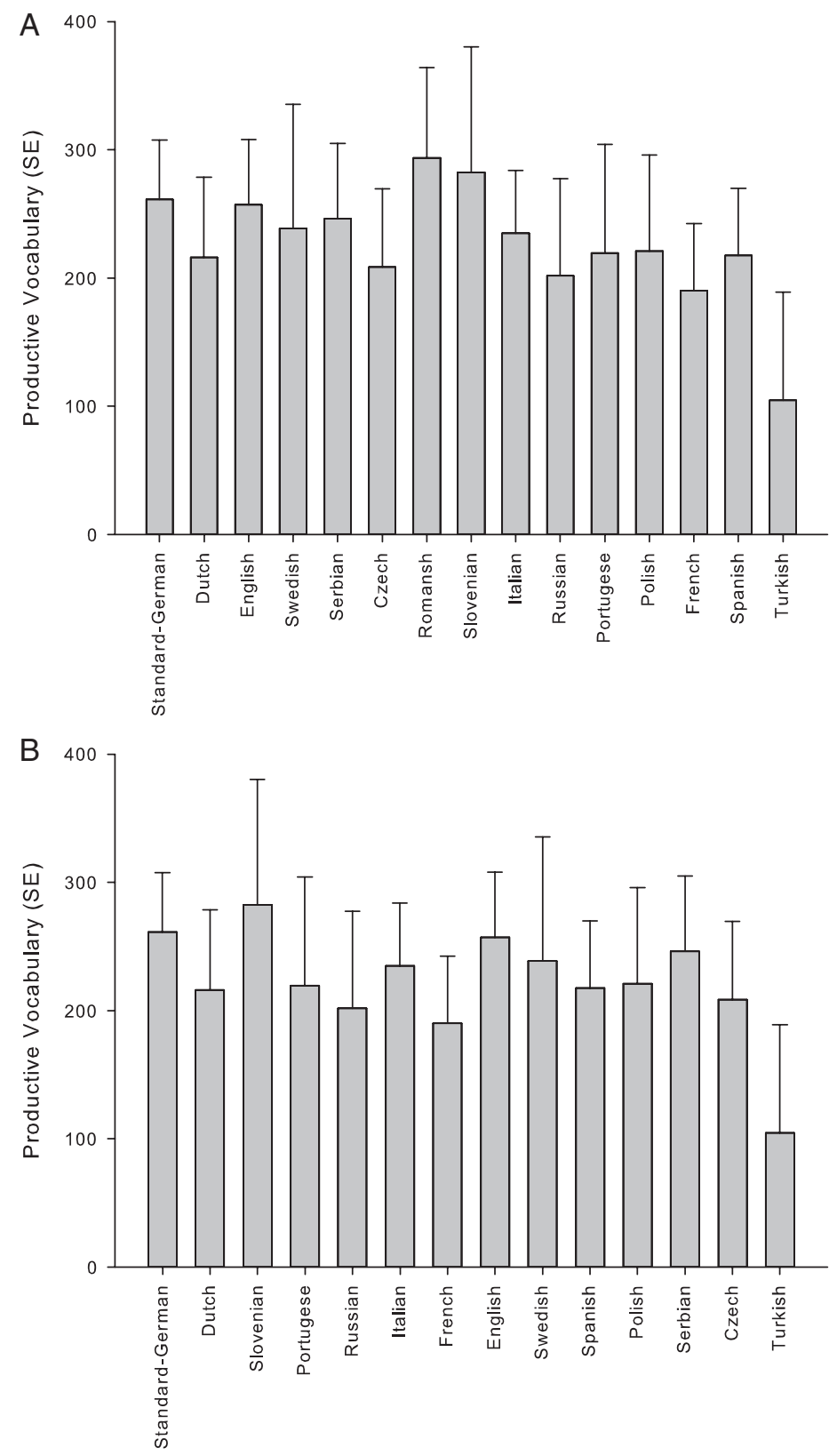

FIGURE 1 Means and standard deviations (error bars) for the children's vocabulary score per other language ordered by ASJP similarity (A) and by wALS Similarity (B) (the graphics includes only those languages for which $\mathrm{n} \geq 3$ ) 


\subsection{Method \\ 3.1.1 Participants}

One hundred and two bilingual children aged 18 to 36 months old (mean age 27 months 21 days; 46 girls) participated in Study 2. None of them had been included in Study 1. As in Study 1, only families in which one parent spoke Swiss German and the other parent spoke a different language were recruited. Since Study 2 assessed the children's vocabulary in both of their languages, only five groups of bilingual children were recruited: Swiss German-Standard German, Swiss German-English, Swiss German-Spanish, Swiss German-French, Swiss German-Italian. Table 2 shows the socio-demographic details on language input and parental education. This sample structure enabled us to carry out group comparisons using ANCOVA s and post-hoc contrasts, similar to the analyses performed by Cote and Bornstein (2014).

\subsubsection{Materials and Procedure}

The method was similar to the one used in Study 1. The children's vocabulary scores were assessed by parental questionnaires based on the German version of the MacArthur Bates Communicative Developmental Inventories (CDI; Szagun et al., 2009). We administered only the 509 open-class words of the German CDI because the languages differ with respect to the number and translations of closed-class items, such as the number of determiners, personal pronouns etc., and comparisons on such words would not be possible. Bilinguals living in Switzerland translated the word list into English, French, Italian, and Spanish. Both parents of each child filled out a questionnaire about the child's vocabulary, in his or her respective language.

We used the same measures of language similarity (ASJP, WALS) as in Study 1. Using the information of both languages' questionnaires we determined

TABLE 2 Demographic details for each language group in Study 2

\section{StandardGerman English French Italian Spanish}

Children

\begin{tabular}{llllll} 
N & 23 & 19 & 20 & 20 & 20 \\
Input Swiss German & 65 & 64 & 67 & 64 & 65 \\
Age (days) & 865 & 834 & 826 & 782 & 844 \\
$\begin{array}{l}\text { Gender (\% girls) } \\
\text { Parents }\end{array}$ & 52 & 47 & 45 & 35 & 45 \\
Education Mother & 9.01 & & & & \\
Education father & 8.66 & 9.27 & 9.15 & 8.85 & 8.7 \\
& & 8.56 & 9.45 & 8.10 & 7.25 \\
\hline
\end{tabular}


the number of productive words in the children's Swiss-German and in their other language. Furthermore, we determined the number of translational equivalents, that is, the number of meanings for which they knew the words in both languages. Based on the level of productive vocabulary, we finally determined the children's major and minor languages. We use the terms 'major' and 'minor' instead of 'dominant' and 'non-dominant' because we regard bilingualism as a continuum, along which children move. The term 'major language' means the language used mostly and does not necessarily refer to the dominant language.

\subsection{Results and Discussion}

The sample sizes in the analyses of the Swiss German and the non-Swiss German languages differ because 31 parents filled out only one of the questionnaires. First, the partial correlations between language similarity and the children's Swiss German vocabulary scores, controlling for age, language exposure and parental education, are similar to what we found in Study 1. For both measures of language similarity, the correlations were significant (ASJP similarity: $r(72)=-.332, p=.004$; wALS similarity $r(72)=.304, p=.008)$.

Second, we carried out a partial Spearman correlation analysis (controlling for age, language exposure and parental education) of language similarity and the children's vocabulary scores in their other language (non-Swiss German). Again, both correlations were significant (ASJP similarity: $r(68)=-.491, p<.001$; WALS similarity $r(68)=.451, p<.001$; see Figure 2 ).

Descriptively these correlations are stronger than the correlations for Swiss German; however, Hittner, May and Silver's (2003) test suggests that the correlations are comparable (ASJP similarity $z=1.345, p=.179$; WALS similarity: $z=1.212, p=.225$ ).

Third, we carried out partial Spearman correlation analysis between language similarity and the children's vocabulary scores in their major and their minor language, controlling for age, language exposure and parental education. The children's major language was Swiss German in 59 of the cases. We found that language similarity affected the acquisition of the minor language (ASJP similarity: $r(62)=-.475, p<.001$; WALS similarity $r(62)=.476, p<.001$ ) to a similar extent as the major language (ASJP similarity: $r(62)=-.324, p=.009$; WALS similarity $r(62)=.304, p=.015$ ), Hittner, May, and Silver's (2003) test (ASJP similarity $z=1.283, p=.199$; WALS similarity: $z=1.453, p=.146$ ).

In a last step, we looked at how language similarity affected the number of translational equivalents, again using partial correlations. We found that the number of cognate translational equivalents was influenced by language similarity (ASJP similarity: $r(62)=-.424, p<.001$; WALS similarity $r(62)=.436$, 


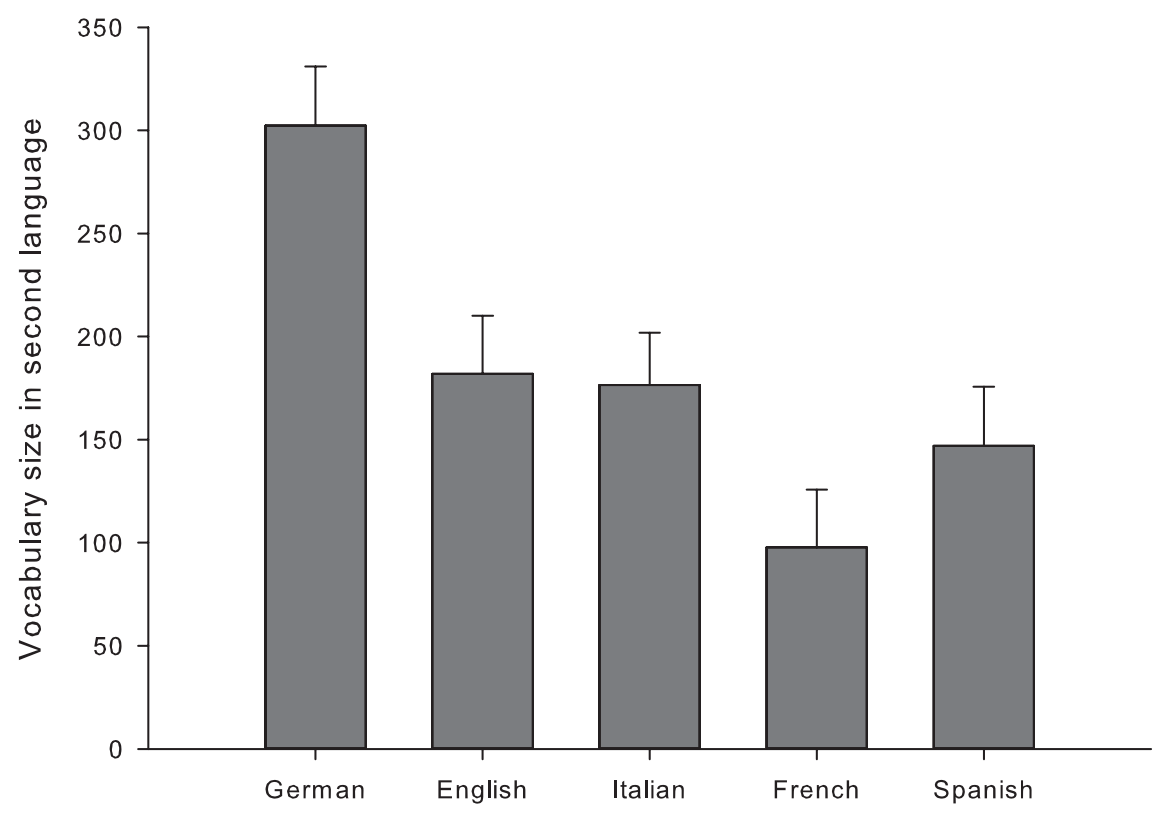

FIGURE 2 Children's average vocabulary score in their non-Swiss German language by language group. Error bars represent SE

$p<.001)$, while the number of non-cognate translational equivalents was not (ASJP similarity: $r(62)=.142, p=.259$; WALS similarity $r(62)=-.176, p=.161$ ). We conclude that the children who were learning two languages that were more similar had learned more cognate translational equivalents.

The results of Study 2 replicate and extend those of Study 1 . These findings suggest that the language similarity effect is robust in bilingual first language acquisition and is observed in both of the children's languages. This contrasts starkly with Cote and Bornstein's (2014) findings, who attested no difference in the vocabulary size of bilinguals speaking English and another language, such as Spanish, Korean, or Japanese. Based on their work, we compared the children's vocabulary scores in both Swiss German and their other language across language groups (Swiss German-Standard German, Swiss German-English, Swiss German-French, Swiss German-Italian, Swiss German-Spanish).

The ANCOvas (controlling for age and parental education and language exposure rates) revealed the following results. First, a significant effect was found of Swiss German vocabulary on the vocabulary score in the other language $\left(F(4,77)=2.714, p=.037, \eta^{2} p=.136\right)$. Second, a significant effect of language group was found for the non-Swiss German vocabulary score 
$\left(\mathrm{F}(4,73)=6.855, p<.001, \eta^{2} p=.297\right)$. Post-hoc contrasts of the children's non-Swiss German vocabulary scores with their other vocabularies revealed that five out of the ten pair-wise comparisons were significant (EnglishGerman: $p=.003$, French-German: $p<.001$, French-Italian: $p=.046$, GermanItalian: $p=0.003$, German-Spanish: $p<.001$ ). No group differences were found for the English-Italian, English-Spanish, French-Spanish and Italian-Spanish groups, all $p>.237$; the difference between English and French was marginally significant: $p=.058$. These findings are in line with the correlations reported above but they contradict Cote and Bornstein's (2014) results. It is difficult to reconcile these conflicting findings. A possible explanation is that particular language combinations in the samples might influence the presence, or absence, of group differences. Another more likely explanation is a difference between Cote and Bornstein's sample and our sample. Bilingual children tested by Cote and Bornstein were growing up in a situation of language compartmentalization, where strict boundaries existed between the societal functions associated with the different languages. The children heard only one language at home (the language of the country of origin) and another language outside their homes (the language of the country of residence). The input patterns for those children thus differed from the input received by the children in our sample, who heard both languages at home. This might explain why Cote and Bornstein did not attest the effect of similarity on bilingual vocabulary development that we report here.

\section{General Discussion}

Bilingual vocabulary development has been shown to be influenced by many factors, such as frequency and type of input or socioeconomic status SES (Hart and Risley, 1995). In the current study we investigated whether phonological and morpho-syntactic similarity between simultaneous bilingual toddler's languages is an additional factor affecting their early vocabulary development. We determined the phonological and morphosyntactic similarity of the two languages for each bilingual group and related these to the size of the productive vocabulary. Our results showed that the more similar a bilingual child's two languages are, the larger the productive vocabulary will be. This effect was reliable and observed in both of the child's two languages. Our findings support those from L2 research on adults (Schepens, Van der Slik, and Hout, 2013; Van der Slik, 2010; Cysouw, 2013). However, as the acquisition routes in sequential L2 learning and simultaneous bilingualism 
are distinct, the similarity in outcome might rely on different mechanisms. Indeed, the major contrast between bilingual first-language acquisition and L2 learning concerns the temporal structure of language learning. L2 learners already know their at least one language (Chenu and Jisa, 20o9). Their word knowledge might serve as a scaffold for vocabulary learning in the second language (MacWhinney, 2008). In contrast, in bilingual first language acquisition concepts as well as word forms are acquired in both languages at the same time, and this affects the build-up of mental representation and activation patterns. Specifically, from a network model perspective (Bybee, 2006; Tomasello, 2003) one could explain the current findings by assuming that the way the representations of linguistic elements and structures are connected to each other (based on similarities in form, function, or both) implies whether and how strongly any particular linguistic item is activated at any moment during speech processing: If two or more items are similar in form and/or function, they are more likely to be co-activated in speech than if they are dissimilar. Therefore, representations of cognates such as Wasser 'water' ['vase] in Standard German and its Swiss-German equivalent ['чаsiər] could be more entrenched and more accessible, which in turn eases production. This is related to the findings of Versloot and Hoekstra (2016), who showed that frequency and phonological similarity of words exert an influence on their cognates in the weaker language. Similarity of form and concept might serve a booster function in terms of conceptual and/or phonological bootstrapping (Carey, 2011; Vihman and Croft, 2007). That is, conceptual bootstrapping of already existing concepts might ease the acquisition of the translational equivalents in the other language, whereas phonological similarity then helps the child to tap into the speech stream by concentrating on those words that are more similar to the patterns of the words already acquired.

Future studies investigating the role of language similarity in bilingual language development therefore need to carefully consider the vocabulary checklists in terms of the cross-linguistic phonological similarity of the items. Furthermore, subsequent research should include the usage frequency of every word on the list in each language to determine whether cross-linguistic phonological similarity indeed has a booster function in acquisition and how word frequency and cross-linguistic similarity interact in vocabulary development. Finally, future research will need to examine whether the language similarity effect remains stable throughout linguistic development, serving a booster function, and whether its magnitude varies in the dominant and the non-dominant language of simultaneous and sequential bilinguals. 
The current study is the first to report a language similarity effect on vocabulary development in bilingual toddlers. This effect is stable and found in both languages (major and minor) in various language constellations. The more similar the two languages, the larger the vocabulary in each of these languages and the higher the number of cognate translational equivalents. This effect is already observable at the beginning of language acquisition in the second year of life until the end of the third year. These results are discussed in the light of the usage-based linguistics tenet that similarity in form and function of words might influence their representations and links between them. In a dynamic network, linguistic signs and structures are associated with each other along structural, functional and semantic aspects.

Consequently, the more similar items are across languages (the more aspects they share), the stronger their associative links become as each occurrence and usage will strengthen the activation link between them. The stronger the connection the easier and faster they will be retrieved, very much resembling a feedback loop (Schmid, 2017). Ultimately this raises the question of how much similarity is required in order to boost the acquisition of words and structures, a question that will have to be answered in future studies on bilingual toddlers' vocabulary development.

\section{References}

Bialystok, Ellen and Gigi Luk. 2012. Receptive vocabulary differences in monolingual and bilingual adults. Bilingualism: Language and Cognition 15(2): 397-401. https:// doi.org/10.1017/S136672891100040X.

Bialystok, Ellen, Gigi Luk, Kathleen F. Peets and Sujin Yang. 2010. Receptive vocabulary differences in monolingual and bilingual children. Bilingualism: Language and Cognition 13(4): 525-531. https://doi.org/10.1017/S1366728909990423.

Borin, Lars. 2013. The why and how of measuring linguistic differences. In Borin, Lars and Anju Saxena (eds.), Approaches to Measuring Linguistic Differences, 3-26. Boston: De Gruyter. http://www.degruyter.com/view/books/9783110305258/9783110 305258.57/9783110305258.57.xml.

Bosch, Laura and Marta Ramon-Casas. 2014. First translation equivalents in bilingual toddlers' expressive vocabulary. Does form similarity matter? International Journal of Behavioral Development 38(4): 317-322. https://doi. org/10.1177/0165025414532559.

Bybee, Joan L. 2006. From Usage to Grammar: The Mind's Response to Repetition. Language 82(4): 711-733. https://doi.org/10.1353/lan.20o6.o186. 
Bybee, Joan L. 2010. Language, usage, and cognition. Cambridge: Cambridge University Press.

Byers-Heinlein, Krista, Christopher T. Fennell and Janet F. Werker. 2013. The development of associative word learning in monolingual and bilingual infants. Bilingualism: Language and Cognition 16(1): 198-205. https://doi.org/10.1017/S1366728912000417.

Carey, Susan. 2011. Précis of The Origin of Concepts. Behavioral and Brain Sciences 34(3): 113-124. https://doi.org/10.1017/So140525X10ooog19.

Cattani, Allegra, Kirsten Abbot-Smith, Rafalla Farag, Andrea Krott, Frederique Arreckx, Ian Dennis and Caroline Floccia. 2014. How much exposure to English is necessary for a bilingual toddler to perform like a monolingual peer in language tests? International Journal of Language and Communication Disorders 49(6): 649-671. https://doi.org/10.1111/146o-6984.12082.

Chenu, Florence and Harriet Jisa. 2009. Reviewing some similarities and differences in L1 and L2 lexical development. Acquisition et Interaction En Langue Étrangère, (Aile... Lia 1), 17-38.

Cote, Linda R. and Marc H. Bornstein. 2014. Productive vocabulary among three groups of bilingual American children: Comparison and prediction. First Language 34(6): 467-485. https://doi.org/10.1177/o14272371456o178.

Cysouw, Michael. 2013. Predicting language-learning difficulty. In Borin, Lars and Anju Saxena (eds.), Approaches to Measuring Linguistic Differences, 57-82. Boston: De Gruyter. http://www.degruyter.com/view/books/9783110305258/9783110305258.57/ 9783110305258.57.xml.

Dale, Philip S. 1991. The validity of a parent report measure of vocabulary and syntax at 24 months. Journal of Speech and Hearing Research 34: 565-571.

David, Annabelle and Li Wei. 20o8. Individual Differences in the Lexical Development of French-English Bilingual Children. International Journal of Bilingual Education and Bilingualism 11(5): 598-618. https://doi.org/10.1080/13670050802149200.

De Houwer, Annick, Marc H. Bornstein and Diane L. Putnick. 2014. A bilingualmonolingual comparison of young children's vocabulary size: Evidence from comprehension and production. Applied Psycholinguistics 35(6): 1189-1211. https:// doi.org/10.1017/So142716412000744.

Fennell, Christopher T., Krista Byers-Heinlein and Janet F. Werker. 2007. Using Speech Sounds to Guide Word Learning: The Case of Bilingual Infants. Child Development 78(5): 1510-1525. https://doi.org/10.1111/j.1467-8624.2007.01080.x.

Gathercole, Virginia C. M. and Enlli M. Thomas. 2009. Bilingual first-language development: Dominant language takeover, threatened minority language take-up. Bilingualism: Language and Cognition 12(2): 213. https://doi.org/10.1017/ S13667289o9oo4015.

Goodman, Judith C., Philip S. Dale and Ping Li. 2008. Does frequency count? Parental input and the acquisition of vocabulary. Journal of Child Language 35(3): 515-531. https://doi.org/10.1017/So305000907008641. 
Graf Estes, Katharine and Jessica F. Hay. 2015. Flexibility in Bilingual Infants' Word Learning. Child Development, $n / a-n / a$. https://doi.org/10.1111/cdev.12392.

Grosjean, François. 1982. Life with two languages : an introduction to bilingualism ([6th print]). Cambridge: Harvard University Press.

Hart, Betty and Todd Risley. 1995. Meaningful differences in the everyday experience of young American children (Vol. xxiii). Baltimore, MD, US: Paul H Brookes Publishing.

Hartsuiker, Robert J., Martin Pickering, and Eline Veltkamp. 2004. Is Syntax Separate or Shared Between Languages?: Cross-Linguistic Syntactic Priming in Spanish-English Bilinguals. Psychological Science 15(6): 409-414. https://doi. org/10.1111/j.o956-7976.2004.00693.x.

Hittner, James B., Kim May and Clayton N. Silver. 2003. A Monte Carlo Evaluation of Tests for Comparing Dependent Correlations. The Journal of General Psychology 13o(2): 149-168. https://doi.org/10.1080/oo221300309601282.

Hoff, Erika, Cyntia Core, Silvia Place, Rosario Rumiche, Melissa Señor and Marisol Parra. 2012. Dual language exposure and early bilingual development. Journal of Child Language 39(1): 1-27. https://doi.org/10.1017/So305000910000759.

Hoff, Erika, Stephanie Welsh, Silvia Place and Krystal M. Ribot. 2014. Properties of dual language input that shape bilingual development and properties of environments that shape duallanguage input. In T. Grüter and J. Paradis (eds.), Input and experience in bilingual development, 119-140. Amsterdam:John Benjamins Publishing Company.

Holman, Eric W., Cecil H. Brown, Søren Wichmann, André Mueller, Viveka Velupillai, Harald Hammarstrom, and Dimitry Egorov. 2011. Automated Dating of the World's Language Families Based on Lexical Similarity. Current Anthropology 52(6): 841-875. https://doi.org/10.1086/662127.

Kalashnikova, Marina, Karen Mattock and Padraic Monaghan. 2014. The effects of linguistic experience on the flexible use of mutual exclusivity in word learning. Bilingualism: Language and Cognition, FirstView, 1-13. https://doi.org/10.1017/ S1366728914000364.

MacWhinney, Brian. 2008. A unified model of language acquisition. In Kroll, Judith F. and Annette M. B. De Groot (eds.), Handbook of Bilingualism: Psycholinguistic Approaches, 49-67. Oxford University Press, USA.

Marchman, Virginia A. and Carmen Martínez-Sussman. 2002. Concurrent validity of caregiver/parent report measures of language for children who are learning both English and Spanish. Journal of Speech, Language, and Hearing Research 45(5): 983997. https://doi.org/10.1044/1092-4388(2002/o8o).

Miser, Tracey M. and Julie M. Hupp. 2012. The Influence of Socioeconomic Status, Home Environment, and Childcare on Child Language Abilities. Current Psychology 31(2): 144-159. https://doi.org/10.1007/s12144-012-9139-o. 
Naigles, Letitia R. Erika Hoff-Ginsberg. 1998. Why are some verbs learned before other verbs? Effects of input frequency and structure on children's early verb use. Journal of Child Language 25(1): 95-120. https://doi.org/null.

Pearson, Barbara Z., Sylvia C. Fernández and Kimbrough D. Oller. 1993. Lexical Development in Bilingual Infants and Toddlers: Comparison to Monolingual Norms. Language Learning 43(1): 93-120. https://doi.org/10.1111/j.1467-1770.1993. tboo174.x.

Pearson, Barbara. Z., Sylvia C. Fernandez, Vanessa Lewedeg and Kimbrough D. Oller. 1997. The relation of input factors to lexical learning by bilingual infants. Applied Psycholinguistics 18(1): 41-58. https://doi.org/10.1017/So142716400oo9863.

Perez-Pereira, Miguel. 2008. Early Galician/Spanish bilingualism: contrasts with monolingualism. In Pérez Vidal Carmen, Maria Juan-Garau and Aurora Bel (eds.), A portrait of the young in the new multilingual Spain, 39-62. Clevedon: Multilingual Matters.

Pierrehumbert, Janet B. 2003. Probabilistic phonology: Discrimination and robustness. In Bod, Rens, Jennifer Hay and Stefanie Jannedy (eds.), Probabilistic linguistics, 177-228. Cambridge: M I T Press.

Place, Silvia and Erika Hoff. 2011. Properties of Dual Language Exposure That Influence 2-Year-Olds' Bilingual Proficiency. Child Development 82(6): 1834-1849. https://doi. org/10.1111/j.1467-8624.2011.0166o.x.

Schelletter, Christina. 2002. The effect of form similarity on bilingual children's lexical development. Bilingualism: Language and Cognition 5(2): 93-107. https://doi. org/10.1017/S1366728902000214.

Schepens, Job, Frans van der Slik and Roeland van Hout. 2013. The effect of linguistic distance across Indo-European mother tongues on learning Dutch as a second language. In Borin, Lars and Anju Saxena (eds.), Approaches to Measuring Linguistic Differences, 199-230. Boston: De Gruyter. Retrieved from http://www.degruyter. com/view/books/9783110305258/9783110305258.57/9783110305258.57.xml.

Schmid, Hans-Jörg. 2017. A framework for understanding linguistic entrenchment and its psychological foundations. In Schmid Hans-Jorg (ed.), Entrenchment and the psychology of language learning: How we reorganize and adapt linguistic knowledge, 9-35. Berlin, Boston: De Gruyter.

Schwartz, Richard G. and Brenda Y. Terrell. 1983. The role of input frequency in lexical acquisition. Journal of Child Language 10(1): 57-64. https://doi.org/10.1017/ So305000900005134.

Silva-Corvalán, Carmen and Jeanine Treffers-Daller (eds.). 2015. Language dominance in bilinguals: issues of measurement and operationalization. Cambridge: Cambridge University Press. 
Swadesh, Morris. 1955. Towards Greater Accuracy in Lexicostatistic Dating. International Journal of American Linguistics 21(2): 121-137.

Szagun, Gisela, Barbara Stumper and Satyam A. Schramm. 20og. Fragebogen zur frühkindlichen Sprachentwicklung (FRAKIS) und FRAKIS-K (Kurzform). Frankfurt: Pearson Assessment.

Thordardottir, Elin. 2011. The relationship between bilingual exposure and vocabulary development. International Journal of Bilingualism 15(4): 426-445. https://doi. org/10.1177/1367006911403202.

Tomasello, Michael. 2003. Constructing a Language: A Usage-Based Theory of Language Acquisition. Harvard University Press.

Unsworth, Sharon. 2015. Amount of exposure as a proxy for dominance in bilingual language acquisition. In Silva-Corvalán, Carmen and Jeanine Treffers-Daller (eds.), Language dominance in bilinguals: issues of measurement and operationalization, 156-173. Cambridge: Cambridge University Press.

Van derSlik, Frans W.P.2010. Acquisition of Dutch as a second language. Studies in Second Language Acquisition 32(3): 401-432. https://doi.org/10.1017/So2722631100ooo21.

Versloot, Arjen P. and Eric Hoekstra. 2016. Attraction between words as a function of frequency and representational distance: Words in the bilingual brain. Linguistics 54(6): 1223-1240. https://doi.org/10.1515/ling-2016-oo28.

Vihman, Marilyn and William Croft. 2007. Phonological development: toward a 'radical' templatic phonology. Linguistics 45(4). https://doi.org/10.1515/LING.2007.021.

Wichmann, Søren, Eric W. Holman, Dik Bakker and Cecil H. Brown. 2010. Evaluating linguistic distance measures. Physica a-Statistical Mechanics and Its Applications 389(17): 3632-3639. https://doi.org/10.1016/j.physa.2010.05.o11.

Wichmann, Søren, André Müller, Annkathrin Wett, Viveka Velupillai, Julia Bischoffberger, Cecil H. Brown, Eric W. Holman, Sebastian Sauppe, Zarina Molochieva, Pamela Brown, Harald Hammarström, Oleg Belyaev, Johann-Mattis List, Dik Bakker, Dmitry Egorov, Matthias Urban, Robert Mailhammer, Agustina Carrizo, Matthew S. Dryer, Evgenia Korovina, David Beck, Helen Geyer, Patience Epps, Anthony Grant, and Pilar Valenzuela. 2013. The AsJP Database (version 16). 